\title{
Anticardiolipin antibodies, livedo reticularis, and major cerebrovascular and renal disease in systemic lupus erythematosus
}

\author{
N J McHUGH, ${ }^{12} \mathrm{~J} \mathrm{MAYMO}^{12}{ }^{2}$ R P SKINNER, ${ }^{2}$ I JAMES,$^{3}$ AND P J MADDISON 2 \& $^{\circ}$
}

From the ${ }^{1}$ Royal National Hospital for Rheumatic Diseases, Bath; the ${ }^{2}$ Arthritis Research Centre, Bath; and $\vec{\circ}_{-}^{\circ}$ the ${ }^{3}$ Royal United Hospital, Bath

SUMMARY Increased levels of IgG anticardiolipin antibodies (ACA) were found in 23 of $98 \pm$ patients $(23 \%)$ with systemic lupus erythematosus. Increased levels of IgM ACA were found less? frequently $(5 \%)$. All four patients with major cerebrovascular events had increased IgG ACA, $\overrightarrow{\vec{O}}$ including the two with highest levels, both of whom were men. Six of nine patients with livedo $\circ$ reticularis had increased IgG ACA. In turn, this clinical feature was associated with cerebrovascular disease in two and renal disease in another six. IgG ACA were not associated with other thromboembolic events, thrombocytopenia, serum IgG, or autoantibodies to $\frac{\mathbb{O}}{2}$ Ro(SSA), La(SSB), U1RNP, Sm, or double or single stranded DNA.

Key words: antiphospholipid antibodies.

Antibodies to cardiolipin (ACA) are markers for recurrent thrombosis and thrombocytopenia ${ }^{1}$ in systemic lupus erythematosus (SLE) and possibly for fetal loss in pregnant patients with the same disorder. ${ }^{2}$ They have been reported in association with cerebrovascular disease ${ }^{3}$ and more recently livedo reticularis ${ }^{4}$ in SLE. An association between livedo reticularis and cerebrovascular disease has been recorded. ${ }^{56}$ Most reported associations, however, have been with highly selected series of patients. Therefore the incidence of ACA measured using an enzyme linked immunosorbent assay (ELISA) technique validated against International Workshop standards ${ }^{7}$ in an unselected series of patients with connective tissue disease, and the possible associations with livedo reticularis and cerebrovascular disease, were sought.

\section{Patients and methods}

Ninety eight patients (13 male, 85 female) fulfilling American Rheumatism Association (ARA) criteria for $S_{L E}^{8}$ were studied. All were being followed up at a connective tissue disease clinic serving as a

Accepted for publication 25 July 1987.

Correspondence to Dr N J McHugh, Royal National Hospital for Rheumatic Diseases, Upper Borough Walls, Bath BA1 1RL, Avon, England. referral base for a large region of south west England. In addition to a comprehensive clinical and serological profile that had already been $\stackrel{\circ}{\mathbb{Q}}$ recorded, an examination of hospital records was $\stackrel{\varrho}{\vec{a}}$ made. Renal disease was defined as the presence of $\overrightarrow{\overrightarrow{0}}$ three or more of the following in the absence of 3 other causes: persistent proteinuria greater than 0.5 ? g/24 hours; oedema requiring diuretic therapy; granular casts; creatinine clearance less than $60 \stackrel{\mathrm{N}}{7}$ $\mathrm{ml} / \mathrm{min}$; persistently raised serum creatinine greater than $124 \mu \mathrm{mol} / \mathrm{l}$; a diastolic blood pressure greater than $90 \mathrm{mmHg}$. Recurrent fetal loss was defined as two or more unexplained fetal losses. Serum was also studied from 66 patients fulfilling proposedo criteria for progressive systemic sclerosis, ${ }^{9} 27^{\circ}$ patients with Felty's syndrome, 12 patients witho chronic localised cutaneous lupus erythematosus, 24 patients with idiopathic valvular heart disease, $100 \mathrm{~N}$ apparently normal blood donors, and an additionaln 16 healthy blood donors with false positive Venereal Disease Research Laboratory (VDRL) test results. ${ }^{\omega}$ Serum samples were stored at $-20^{\circ} \mathrm{C}$ until tested. Anticardiolipin antibodies were measured using a? solid phase ELISA technique. Cardiolipin (Sigma吕 Chemical Co, Poole, Dorset, UK) $40 \mu \mathrm{l}$, at $\mathrm{a}_{0}^{-}$ concentration of $50 \mu \mathrm{g} / \mathrm{ml}$ methanol, was allowed to evaporate onto polystyrene plates (Nunc Immuno I) for one hour. Plates were blocked with $10 \%$ fetal $\frac{\rho}{\mathbb{Q}}$ 
calf serum (FCS) in phosphate buffered saline (PBS) for two hours before addition of $100 \mu \mathrm{l}$ of serum diluted $1 / 50$ in $10 \%$ FCS/PBS to duplicate wells for 90 minutes, followed by either goat antihuman IgG ( $\gamma$ chain specific) or goat antihuman $\operatorname{IgM}(\mu$ chain specific) alkaline phosphatase conjugate (Sigma) diluted 1/1000 in FCS/PBS for one hour, with PBS washes between each stage. After further washing the substrate, $p$-nitrophenylphosphate, (Sigma) at 1 $\mathrm{mg} / \mathrm{ml}$ in carbonate buffer ( $\mathrm{pH} \mathrm{9.6)}$ was finally added and absorbance measured at $410 \mathrm{~nm}$ with an ELISA plate reader (Dynatech) when the positive control reached $1 \cdot 0$. Four standards were included on each plate and results expressed as standard deviations (SD) above the mean of 100 normal sera.

The assay was validated against International Workshop standards ${ }^{7}$ obtained from the lupus research group at St Thomas's Hospital, whose report on the validity of our results based on correlation with their own was as follows: IgG ACA linear regression slope $0 \cdot 786$, interrun coefficient of determination $\mathrm{R}^{2}=89 \% \quad(\mathrm{p}<0.001)$; IgM linear regression slope $0.511, R^{2}=86 \%(p<0 \cdot 001)$.

Each SLE serum was assayed for single stranded (ss) DNA antibodies using a similar ELISA technique but with plates precoated with poly-L-lysine (Sigma), ssDNA (Sigma) at a concentration of 10 $\mu \mathrm{g} / \mathrm{ml}$ in PBS, $0.5 \%$ bovine serum albumin in PBS as a blocking agent, and PBS/Tween $(0.05 \% \mathrm{v} / \mathrm{v})$ as diluent for serum, antihuman IgG conjugate, and for washing the plates. Double stranded (ds) DNA antibodies were measured with an ELISA technique (Walker Laboratories Ltd, Cambridge, UK) using an IgG conjugate. Total serum IgG and IgM were measured on an automated laser-nephelometer (Hyland Disc 200). Each SLE serum was also screened for antibodies to the soluble nuclear antigens $\mathrm{Ro}(\mathrm{SSA}), \mathrm{La}(\mathrm{SSB}), \mathrm{U} 1 \mathrm{RNP}$, and Sm using Ouchterlony double diffusion and counterimmunoelectrophoresis.

Statistical methods were the $\chi^{2}$ test, MannWhitney U test, and Spearman's rank correlation.

\section{Results}

Twenty three of 98 patients $(23 \%)$ with SLE had raised IgG ACA (i.e., greater than $2 \mathrm{SD}$ above the mean of 100 normal sera) (Fig. 1). Low levels were found in three patients $(5 \%)$ with systemic sclerosis, and one patient with Felty's syndrome who also had thrombotic thrombocytopenic purpura. All patients with chronic localised cutaneous lupus or idiopathic valvular heart disease had normal levels. Moderately increased levels were found in three $(19 \%)$ false positive VDRL sera. Increased IgM ACA were less prevalent $(5 \%)$ in SLE and correlated weakly with serum $\operatorname{IgM}(r=0 \cdot 328, p<0 \cdot 05)$. Increased $\operatorname{IgM}$ ACA were found in $2 \%$ (systemic sclerosis) to $13 \%$ (false positive VDRL) of other control groups.

The clinical associations of increased IgG ACA were with major cerebrovascular events and with livedo reticularis (Table 1). Although there was no significant association with cerebral involvement as defined by ARA criteria ${ }^{8}$ (i.e., the occurrence of seizures or psychosis), there was a highly significant association of increased IgG ACA with the occurrence of cerebrovascular accidents $(p=0 \cdot 001$, MannWhitney U test). Four patients had major cerebrovascular events, and all had increased IgG ACA, the two with the highest levels being men (Table 2). These events all occurred at a young age (range 25-33) and are described below.

\section{CAS E A}

In 1982 this man, now aged 29, presented with a fever, increasing myalgia and arthralgia, and generalised lymphadenopathy. He rapidly developed cerebellar signs with scanning speech, an incomplete right third cranial nerve palsy, and bilateral upper motor neurone weakness. His antinuclear antibody (ANA) test, Coombs test, and DNA binding were all positive. A computed tomographic (CT) scan, lumbar puncture, and arteriography were normal. Visual evoked potentials were reduced and delayed. He responded well to treatment, initially with pulse methylprednisolone and cyclophosphamide, followed by oral prednisolone and azathioprine, but had residual cerebellar and pyramidal dysfunction, and hypertension requiring treatment with captopril. The following year he developed a photosensitive rash on the face, hands, and feet, which showed typical changes of SLE when biopsied.

\section{CASE B}

In 1986 this 33 year old man was first admitted with symptoms of arthralgia, weight loss, and central

Table 1 Clinical associations with $\operatorname{Ig} G A C A$ in SLE

\begin{tabular}{lll}
\hline & $\begin{array}{l}\text { Increased } \\
\text { IgG ACA }\end{array}$ & $\begin{array}{l}\text { Normal } \\
\text { IgG } A C A\end{array}$ \\
\hline No of patients & 23 & 75 \\
Cerebrovascular accident & 4 & 0 \\
CNS involvement & 9 & 17 \\
Livedo reticularis & 6 & 3 \\
Renal disease & 6 & 9 \\
Recurrent fetal loss & 1 & 2 \\
Deep vein thrombosis & 3 & 6 \\
Pulmonary embolism & 1 & 4 \\
Thrombocytopenia & 2 & 11 \\
\hline
\end{tabular}

${ }^{*}$ Central nervous system (CNS) involvement as defined by ARA criteria. $^{8}$ 
chest pain and was found to have pericarditis, an ulna nerve neuropathy, prominent livedo reticularis over arms and legs, and a rapidly developing psychosis. The presence of lymphopenia, a positive ANA test, and abnormal DNA binding helped confirm the diagnosis of SLE. The development of colour blindness was also a feature. He responded to corticosteroid treatment but while still receiving $12.5 \mathrm{mg}$ of prednisolone was readmitted four months later with sudden onset of right sided weakness and slurred speech. He became confusects. and disorientated, was noted to have a soft exudate in the left fundus, prominent weakness and wastinges of the right side of the tongue, and a severe righto hemiparesis. He was considered to have diffuse bilateral cerebral and brain stem lesions. A CT scans showed multiple areas of hypodensity in the lef internal capsule and around the frontal horn of thes

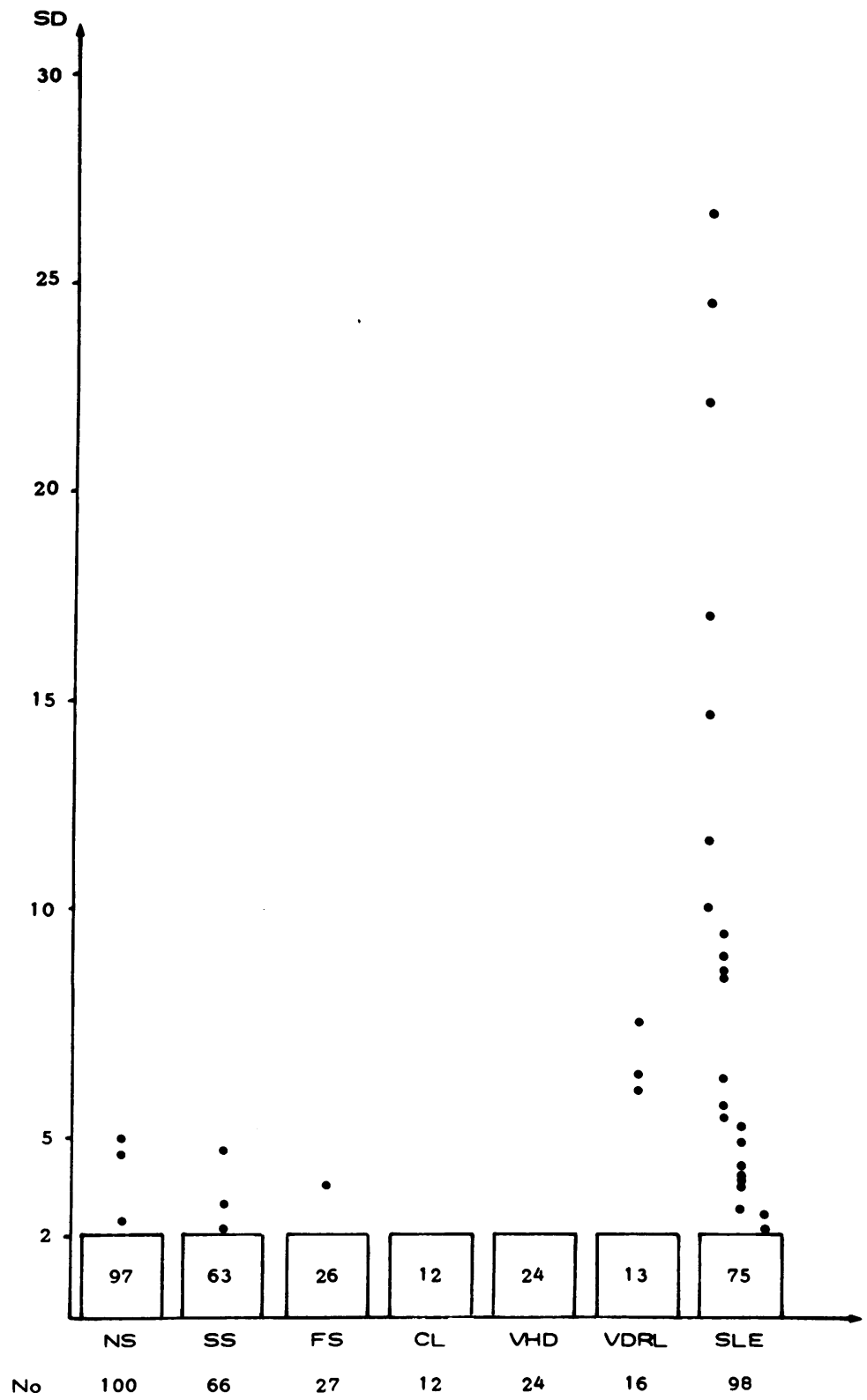

Fig. 1 IgG anticardiolipin antibody $(A C A)$ units in patients with systemic lupus erythematosus (SLE), progressive systemic sclerosis (SS), Felty's syndrome (FS), cutaneous lupus erythematosus $(C L)$, idiopathic valvular heart disease (VHD), false positive VDRL sera (VDRL), and normal sera (NS). 
Table 2 Clinical features of 23 patients with SLE ranked in order of increased $\operatorname{IgG} A C A$

\begin{tabular}{|c|c|c|c|c|c|c|}
\hline$A C A$ level & Case & Sex & $C V A$ & $L R$ & Renal & Other \\
\hline \multirow[t]{3}{*}{ High $(>20 S D)$} & A & $\mathbf{M}$ & Yes & - & - & - \\
\hline & B & $\mathbf{M}$ & Yes & Yes & - & Mononeuritis \\
\hline & $\mathrm{C}$ & $\mathrm{F}$ & - & - & - & - \\
\hline \multirow[t]{13}{*}{ Moderate $(4-20 \mathrm{SD})$} & $\mathrm{D}$ & $\mathrm{F}$ & - & - & - & Psychosis \\
\hline & $\mathrm{E}$ & M & - & - & - & - \\
\hline & $\mathrm{F}$ & $\mathbf{F}$ & Yes & Yes & - & DVT, PE \\
\hline & G & $\mathbf{F}$ & - & - & - & - \\
\hline & $\mathrm{H}$ & $F$ & - & - & - & - \\
\hline & I & $\mathbf{F}$ & Yes & - & - & 9 fetal losses \\
\hline & $\mathbf{J}$ & $\mathrm{F}$ & - & - & - & - \\
\hline & $\mathbf{K}$ & $\mathrm{F}$ & - & Yes & Yes & OBS \\
\hline & $\mathrm{L}$ & $\mathrm{F}$ & - & - & - & - \\
\hline & $\bar{M}$ & $\mathrm{~F}$ & - & - & - & - \\
\hline & $\mathrm{N}$ & $\mathrm{F}$ & - & - & - & Psychosis \\
\hline & $\mathrm{O}$ & $\mathrm{F}$ & - & - & - & - \\
\hline & $\mathbf{P}$ & $\mathrm{F}$ & - & - & Yes & - \\
\hline \multirow[t]{7}{*}{ Low (2-4SD) } & $\mathrm{Q}$ & $\mathrm{F}$ & - & Yes & Yes & OBS, Ep \\
\hline & $\mathrm{R}$ & $\mathrm{F}$ & - & Yes & Yes & Ep, Psychosis, DVT \\
\hline & $\mathrm{S}$ & $F$ & - & - & - & - \\
\hline & $\mathrm{T}$ & $\mathrm{F}$ & - & - & - & Psychosis \\
\hline & $\mathrm{U}$ & $\mathrm{F}$ & - & - & Yes & - \\
\hline & V & $\mathrm{F}$ & - & - & - & - \\
\hline & W & $\mathrm{F}$ & - & Yes & Yes & - \\
\hline
\end{tabular}

CVA = cerebrovascular accident; $L R=$ livedo reticularis; $D V T=$ deep vein thrombosis; $P E=$ pulmonary embolus; $O B S=$ organic brain syndrome; Ep=epilepsy.

right lateral ventricle, consistent with multiple infarcts. Treatment with pulse methylprednisolone and cyclophosphamide was eventually effective after an initial deterioration complicated by fever and a metabolic acidosis. Now receiving a maintenance dose of prednisolone and cyclophosphamide, he has severe residual neurological deficits with impairment of intellectual function, colour blindness, a right hemiparesis, and a left ulna nerve palsy.

\section{CASE F}

A 27 year old woman was diagnosed as having SLE at the age of 20 . Features included arthritis, Raynaud's phenomenon, a photosensitive malar rash, previous deep vein thrombosis, positive ANA test and DNA binding, and an abnormal electroencephalogram. She had had one induced abortion the previous year, one spontaneous abortion at 10 weeks' gestation the following year, and one successful pregnancy complicated by severe preeclampsia with a normal child delivered preterm by Caesarean section the year after. At age 25 she was admitted with a suspected right ulnar nerve neuropathy, followed later by a sudden headache and slurred speech. A CT scan was normal. One week later there was further severe headache, drowsiness, loss of speech, right pseudobulbar palsy, and progressive weakness of the right arm. A CT scan showed an intracerebral haemorrhage with a sylvian fissure clot rupturing into the ventricle. Treatment with pulse methylprednisolone coincided with a good recovery apart from residual slurred speech and severe wasting of the intrinsic muscles of the right hand. The presence of livedo reticularis was first recorded during the initial cerebral event and has been persistent since. Another course of pulse methylprednisolone and cyclophosphamide was required in 1986 for a further cerebral flare.

\section{A S E I}

A 27 year old woman had a five year history of arthritis and pleurisy and nine miscarriages, each occurring consecutively at an earlier gestational age apart from one successful pregnancy with delivery by Caesarean section preterm during her third pregnancy. She presented recently with a brief history of headache, expressive dysphasia, and a right hemiparesis. A butterfly rash and generalised lymphadenopathy were noted, and laboratory tests showed a weakly positive ANA test but normal DNA binding. A CT scan showed slightly decreased attenuation in the left parietal region consistent with a left middle cerebral infarct. Moderate recovery followed treatment with pulse methylprednisolone.

Cerebral involvement was also present in six other patients with SLE with raised IgG ACA (Table 2). 
Table 3 Obstetric history of 69 women with SLE

\begin{tabular}{lcc}
\hline & Increased ACA $^{*}$ & Normal $A C A$ \\
\hline No & 18 & 51 \\
Nulliparous & 8 & 14 \\
Parous & 10 & 37 \\
No of pregnancies & 26 & 99 \\
Induced abortions & 1 & 5 \\
Fetal losses & $10^{\dagger}$ & 13 \\
Fetal loss (\%) & 40 & 14 \\
Recurrent fetal loss & 1 & 3 \\
\hline
\end{tabular}

${ }^{*}$ Three patients with increased IgG and IgM ACA, 14 with increased IgG alone, and one with increased IgM alone. †Nine fetal losses occurring in one patient (case I).

Three patients with livedo reticularis and major renal disease had organic brain syndromes; one had frequent memory losses and a serious suicide attempt, another had stupor and two grand mal fits during a major systemic flare, and the third had recurrent episodes of psychosis, stupor, and grand mal fits. Three others had profound depression requiring psychiatric referral.

Of nine SLE patients with livedo reticularis, six had increased IgG ACA levels $(p=0 \cdot 004$, MannWhitney $U$ test). Two of these had major cerebrovascular events coincident with the first record of the livedo, and the other four had renal disease. Of the other three patients with livedo reticularis and normal IgG ACA levels, two had renal involvement and the other hypertension. Livedo reticularis was strongly associated with renal disease $\left(\chi^{2} ; \mathrm{p}<0.001\right)$ and also with cerebrovascular involvement $\left(\chi^{2}\right.$; $\mathrm{p}<0.05)$. The renal disease in the six patients with livedo reticularis included heavy proteinuria, active urinary sediment, and in the four cases that were biopsied, active glomerulonephritis. IgG ACA alone were not associated with renal disease.

A complete obstetric history was obtained by either questionnaire or interview for 69 out of 85 women with SLE (Table 3). Among the 47 women who became pregnant there was a total of 125 pregnancies with a fetal loss rate of $18 \%$. Only four women had two or more fetal losses during pregnancy. Three of these suffered two fetal losses each and had normal ACA levels, one woman (case I) suffered nine fetal losses and had increased IgG ACA with IgM ACA levels at the upper limit of normal. Of the other 17 women with either raised IgG ACA or IgM ACA, eight were nulliparous, of whom at least three were infertile, eight had 13 successful pregnancies with no fetal losses, and one patient (case F) had one successful pregnancy, one spontaneous abortion, and one induced abortion.

Raised IgG ACA were not associated with other thromboembolic events such as deep vein throm- bosis, or with thrombocytopenia (platelet count less than $\left.150000 \times 10^{9} / 1\right)$, or antibodies to $\operatorname{Ro}(S S A)$ ? $\mathrm{La}(\mathrm{SSB}), \mathrm{Sm}$, or U1RNP. There was no correlation of IgG ACA with serum IgG, anti-ssDNA, or anti? dsDNA.

\section{Discussion}

Cerebral involvement in SLE is common witlo neuropsychiatric features being recorded in $40-60 \%$ of cases. ${ }^{10-13}$ Cerebrovascular accidents occur less. often with an incidence of between $2 \%$ an 4 $10 \% .^{1011} 13$ Four out of 98 patients in this series (4\%) had major cerebrovascular events with resio dual neurological deficits. All these events occurred at a young age (range 25-33). Evidence of a mork generalised systemic illness occurred in all four, and in two patients a peripheral neuropathy and lived $\vec{\oplus}$ reticularis were prominent accompaniments. A CT scan demonstrated cerebral infarction in two cases $\overrightarrow{-}$ cerebral haemorrhage in one, and was normal in the other.

Livedo reticularis is a cyanotic discoloration of the skin with a characteristic network pattern. Alf association between cerebrovascular lesions apido livedo reticularis has previously been noted. ${ }^{56}$ I ${ }^{2}$ least one of the six cases initially described $\vec{\exists} \times$ Sneddon a peripheral neuropathy also occurred. another series of four cases associated with repeate cerebrovascular accidents a CT scan showed multio focal cerebral infarction and cortical atrophy in alo cases. ${ }^{6}$ Nine of our patients $(9 \%)$ had livedo reticularis, eight of these having severe cerebro을 vascular or renal disease, or both, and the nintb having hypertension. Livedo reticularis therefore is truly a cutaneous marker for potentially life threatening systemic disease in SLE.

When an ELISA assay validated against Intero national Workshop standards (see 'Patients an methods') was used IgG ACA were found in $23 \%$ oळ our SLE study group, an incidence slightly less than other reports but probably reflecting the selection of cases. All four patients with cerebrovascular diseases had raised IgG ACA ( $p=0.001$, Mann-Whitney test), including two men who had the highest levels There was no association with other thromboembolic events such as deep vein thrombosis of pulmonary embolism. Six of nine patients with livedo reticularis, however, had raised IgG ACAD $(p=0.004$, Mann-Whitney U test). We were unable to confirm the reported associations with thrombo $\frac{\bar{D}}{\mathrm{D}}$ cytopenia $^{1}$ but like Harris et al we found nơ correlation of IgG ACA with either anti-ssDNA oro anti-dsDNA. IgM ACA were less prevalent $(5 \%)$ in? SLE. In addition there was a weak correlatiorn between IgM ACA and total serum IgM. 
The mechanism by which ACA or the closely associated lupus anticoagulant ${ }^{14}$ are associated with thrombosis is uncertain but probably in part involves interference with endothelial or platelet function by binding phospholipid. Any mechanism must also explain why increased ACA are present in some patients with no apparent vasculitic or thrombotic complications. Livedo reticularis is a cutaneous marker for generalised systemic vasculitis and the additional presence of antiphospholipid antibodies may potentiate vascular damage, leading in some patients to major cerebrovascular events.

It is of interest that true vasculitis was found infrequently at necropsy in brains of patients with cerebral lupus, occurring in only three of 26 cases. ${ }^{15}$ It is more prevalent, however, in those with active cerebral disease at the time of death, and more prevalent $(40 \%)$ in those with cerebral haemorrhage, especially subarachnoid haemorrhage $(70 \%) .{ }^{16}$ This implies that immune mechanisms are responsible for these more major complications, and may well involve anticardiolipin antibodies.

Recurrent fetal loss in pregnancy is associated with the lupus anticoagulant. ${ }^{17} 18$ ACA are claimed to be predictors of fetal distress or fetal death in pregnant patients with SLE, ${ }^{2}$ though there is some doubt as to the validity of the ELISA technique used in this study. ${ }^{19}$ In this series of 69 women with SLE, whose obstetric histories were obtained in full, the phenomenon of recurrent fetal loss in association with increased ACA was rare, occurring in only one patient.

In conclusion, in SLE there is a subset of patients who have major systemic disease with cerebrovascular and renal involvement, and who are identified by the presence of the cutaneous marker livedo reticularis and raised levels of IgG anticardiolipin antibodies.

We thank Professor P Dieppe and Dr T Wallington for permission to study their patients and Mrs Jean Wright for preparing the manuscript.

\section{References}

1 Harris E N, Gharavi A E, Boey M L, et al. Anticardiolipin antibodies. Detection by radioimmunoassay and association with thrombosis in systemic lupus erythematosus. Lancet 1983; ii: $1211-4$.

2 Lockshin M D, Druzin M L, Goei S, et al. Antibody to cardiolipin as a predictor of fetal distress or death in pregnant patients with systemic lupus erythematosus. $N$ Engl J Med 1985; 313: $152-6$.

3 Harris E N, Gharavi A E, Asherson R A, Boey M L, Hughes G $R$ V. Cerebral infarction in systemic lupus: association with anticardiolipin antibodies. Clin Exp Rheumatol 1984; 2: 47-51.

4 Englert H J, Loizou S, Hughes G R V, Aber V, Walport M J. Livedo reticularis and lupus erythematosus-clinical and immunological associations [Abstract]. Br J Rheumatol 1986; 25(suppl 2): 96.

5 Sneddon I B. Cerebrovascular lesions and livedo reticularis. $\mathrm{Br}$ J Dermatol 1965; 77: 180-5.

6 Rumpl E, Neuhofer J, Pallua A, et al. Cerebrovascular lesions and livedo reticularis (Sneddon's syndrome)-a progressive cerebrovascular disorder? J Neurol 1985; 231: 324-30.

7 Harris E N, Gharavi A E, Patel S P, Hughes G R V. Evaluation of the anticardiolipin antibody test: report of an International Workshop held on 4th April 1986. Clin Exp Immunol 1987; 68: 215-22.

8 Tan E M, Cohen A S, Fries J F, et al. The 1982 revised criteria for the classification of systemic lupus erythematosus. Arthritis Rheum 1982; 25: 1271-7.

9 Masi A T, Rodnan G P, Medgser T A J, et al. Preliminary criteria for the classification of systemic sclerosis (scleroderma). Arthritis Rheum 1980; 23: 581-90.

10 Grigor R, Edmonds J, Lewkonia R, Bresnihan B. Hughes G R V. Systemic lupus erythematosus. A prospective analysis. Ann Rheum Dis 1978; 37: 121-8.

11 Abel T, Gladman D D, Urowitz M B. Neuropsychiatric lupus. J Rheumatol 1980; 7: 325-33.

12 Estes D, Christian C L. The natural history of systemic lupus erythematosus by prospective analysis. Medicine (Baltimore) 1971; 50: 85-95.

13 Gibson T, Myers A R. Nervous system involvement in systemic lupus erythematosus. Ann Rheum Dis 1976; 35: 398-406.

14 Harris E N, Loizou S, Englert $\mathrm{H}$, et al. Anticardiolipin antibodies and lupus anticoagulant. Lancet 1984; iii: 1099.

15 Johnson R, Richardson E. The neurological manifestations of systemic lupus erythematosus. Medicine (Baltimore) 1968; 47: 337-69.

16 Ellis S G, Verity M A. Central nervous system involvement in systemic lupus erythematosus: a review of neuropathologic findings in 57 cases 1955-1977. Semin Arthritis Rheum 1979; 8: 212-21.

17 Lubbe W F, Butler W S, Palmer S J, Liggins G C. Lupus anticoagulant in pregnancy. $\mathrm{Br} J$ Obstet Gynaecol 1984; 91: $357-63$.

18 Branch D W, Scott J R, Kockenour N K, Hershgold E. Obstetric complications associated with the lupus anticoagulant. N Engl J Med 1985; 313: 1322-6.

19 Lenzi $R$, Rand $\bar{J} \bar{H}$, Spiera $\bar{H}$. Ānticardiolipin antibodies in pregnant patients with systemic lupus erythematosus. $N$ Engl $J$ Med 1986; 314: 1392. 